\title{
Taller de formación interdisciplinario: «Las tardes de jóvenes investigadores del IFEA». Balance del primer año, y perspectivas para 2015
}

\section{Cyriaque Hattemer y Alice Langlois}

\section{OpenEdition \\ Journals}

Edición electrónica

URL: http://journals.openedition.org/bifea/7450

DOI: 10.4000/bifea.7450

ISSN: 2076-5827

Editor

Institut Français d'Études Andines

Edición impresa

Fecha de publicación: 1 abril 2015

Paginación: 155-161

ISSN: 0303-7495

Referencia electrónica

Cyriaque Hattemer y Alice Langlois, «Taller de formación interdisciplinario: «Las tardes de jóvenes investigadores del IFEA». Balance del primer año, y perspectivas para 2015 », Bulletin de l'Institut français d'études andines [En línea], 44 (1) | 2015, Publicado el 08 mayo 2015, consultado el 05 noviembre 2020. URL : http://journals.openedition.org/bifea/7450 ; DOI : https://doi.org/10.4000/ bifea.7450

\section{(c) (1) $\odot$}

Les contenus du Bulletin de l'Institut français d'études andines sont mis à disposition selon les termes de la licence Creative Commons Attribution - Pas d'Utilisation Commerciale - Pas de Modification 4.0 International. 


\section{Eventos}

\section{TALLER DE FORMACIÓN INTERDISCIPLINARIO: «LAS TARDES DE JÓVENES INVESTIGADORES DEL IFEA». BALANCE DEL PRIMER AÑO, Y PERSPECTIVAS PARA 2015}

Lima, año 2014

En 2014, un grupo de jóvenes investigadores ha formado un espacio de intercambio científico, interdisciplinario dentro del IFEA intitulado: «Las tardes de jóvenes investigadores del IFEA». Consiste en un encuentro mensual abierto a todos los estudiantes en ciencias humanas (o humanidades) que desean compartir e intercambiar conocimientos sobre las sociedades y los países «andinos». Diez reuniones permitieron durante el año 2014 intercambiar, en un ambiente amistoso, resultados de investigación, análisis críticos, metodología de investigación y referencias bibliográficas. Este texto relata el proceso de construcción del grupo, es decir cómo fue pensado y organizado pero también trata de realizar un balance abierto sobre las expectativas para 2015.

\section{PARA LA COMPRENSIÓN DE LOS PAÍSES «ANDINOS». UN ESPACIO DE COOPERACIÓN, SOCIABILIZACIÓN Y AUTOFORMACIÓN CIENTÍFICA}

Las tardes de jóvenes investigadores del IFEA, tienen por objetivo principal la comprensión de las sociedades «andinas». El grupo nace de la observación de 5 estudiantes $^{1}$ de la necesidad de beneficiar de un espacio para exponer sus resultados de investigación e intercambiar entre colegas de distintas disciplinas. El primer encuentro se realizó el 28 de febrero de 2014 cuando se reunieron

1 Raúl Alencar (PUCP/IFEA); Doris Buu-Sao (Science Po Paris/IFEA); Maud Delevaux (EHESS/IFEA); Cyriaque Hattemer (IFEA/Paris 1/UMR Prodig); Alice Langlois (EHESS/CERMA/IFEA) 
jóvenes investigadores del IFEA presentes este día en Lima². En esta primera sesión, cada uno presentó sus necesidades, expectativas e ideas para crear un grupo. La conversación permitió definir tres ejes de trabajo:

- teoría y epistemología en ciencias sociales,

- metodología e interpretación del mundo social,

- profesionalización del «joven» investigador y herramientas de investigación.

Gracias al apoyo del IFEA, las «tardes de jóvenes investigadores» son un seminario abierto a todos los jóvenes investigadores en ciencias humanas y a los profesores quienes desean ofrecer su tiempo para contribuir a este proyecto. El castellano prevalece sobre el francés, lo que permite a los estudiantes francófonos consolidar el idioma de manera académica y facilita el intercambio entre investigadores americanistas. Contamos actualmente aproximadamente con 30 estudiantes e investigadores dentro de «nuestra pequeña red».

Espacio de cooperación, la motivación de cada participante es extender y consolidar sus conocimientos para realizar de la mejor manera su tesis de doctorado o master. En esta perspectiva, el grupo propone reservar un espacio - la salle Charentey unos días - los viernes por la tarde - para presentar los trabajos científicos y dedicarse al libre debate de ideas científicas. Los participantes están invitados a compartir elementos del contexto histórico, sociológico, referencias bibliográficas, métodos y consejos útiles a todo tipo de investigación. Incitamos al diálogo con la intención de desarrollar la cooperación donde cada intervención individual enriquece las expectativas del grupo.

La riqueza de estas interacciones es el fruto de las diversidades de los participantes:

- A los conceptos teóricos y metodológicos de cada uno, vinculados a distintas disciplinas

- A las problemáticas de las diferentes tesis que movilizan una gran variedad de objetos y campos temáticos,

- A las diversas experiencias y carreras universitarias (de la Física a la Antropología, de las Ciencias Políticas a la Historia...), por la curiosidad de cada uno por lecturas especializadas, etc.

Es todo este conjunto de particularidades que se quiere compartir para ayudar en los procesos de investigación. Por ejemplo, los investigadores no disponen siempre de las «herramientas» para interpretar y entender temas de otras disciplinas. Intercambiar sobre estas materias permite dar nuevas perspectivas en la orientación de los trabajos. En un primer momento, los estudiantes deben identificar sus propios problemas, para luego exponerlos en las reuniones. No se trata de reemplazar el director de tesis, pero tratamos de ayudar al estudiante a identificar sus dificultades y ayudarle a formular preguntas más precisas.

2 Además de los estudiantes citados en la primera nota: Chloé Constant (UAM-Xochimilco/IFEA); Chloé Paux (IdA); David Rengifo (Univ. Rennes/IFEA); Jérémy Robert (PUCP/IFEA); Natalí Durand (Flacso Ecuador/IFEA). 
Espacio de socialización, ese grupo quiere contribuir a brindar soluciones a una forma de aislamiento de los jóvenes investigadores durante sus estadías en el extranjero. En el trascurso de este periodo de trabajo de campo, en la mayoría de los casos, no benefician de la formación científica: vida del laboratorio, formaciones de las escuelas doctorales, seminarios... Beneficiando de la red y la estructura del IFEA, esta iniciativa constituye una respuesta a esa realidad.

Espacio de «auto-formación», estas sesiones quieren incentivar experiencias en las cuales los jóvenes investigadores pueden mejorar su carrera profesional. Las reuniones son un espacio donde cada uno tiene la oportunidad de progresar en su expresión oral, formular sus preguntas de tesis, moderar un debate, redactar informes, corregir un texto en curso de redacción...

\section{TRES FÓRMULAS PARA DESARROLLAR INTERCAMBIOS CIENTÍFICOS ENTRE JÓVENES INVESTIGADORES}

Las reuniones se desarrollan en general el último viernes de cada mes. Según la agenda de los investigadores, de sus demandas, necesidades y de las estadías que tienen en el IFEA, se intenta ser flexibles y adaptar el calendario de trabajo. Cada reunión involucra tres participantes:

Un moderador presenta la sesión, el tema del día, los exponentes y sus trayectorias. Un secretario registra la reunión y redacta una síntesis de los temas desarrollados. Un responsable de comunicación se encarga de la difusión de los datos del evento. Después de un año de reuniones hemos identificado tres fórmulas:

\section{Fórmula 1: Presentación de temas de investigación}

Estas reuniones ayudan a la preparación de una intervención en un coloquio, de una publicación o de una sustentación de tesis. Para favorecer la interacción entre los oyentes, se pidió a los exponentes entregar previamente el resumen de su presentación, su currículo y sus referencias bibliográficas. Según los casos:

Un investigador realiza una presentación de sus trabajos en 30/45 minutos.

Dos investigadores intervienen en 20/25 minutos acerca de una misma problemática, área geográfica común, o campo disciplinario común.

Siguen a esas presentaciones una discusión de una hora aproximadamente. Según las disponibilidades, investigadores confirmados están cordialmente invitados a ayudar a poner en perspectiva las ideas desarrolladas en las presentaciones.

\section{Formula 2: Charla acerca de una temática transdisciplinaria}

Cuando se expresa la necesidad, el grupo puede trabajar cuestiones específicas. En este caso se favore una perspectiva multidisciplinaria. Estas sesiones pueden permitir por ejemplo la preparación de un coloquio y contar con la presencia de especialistas internacionales presentes en el Perú. Por ejemplo, el 4 de abril de 2014 se ha debatido sobre la cuestión de la ética en la investigación. El 7 de noviembre de 2014, el grupo se reunió para un seminario temático «ciudades y 
conflictos» contando con la presentación de Alexis Sierra (Université de Cergy Pontoise/UMR Prodig) y Mathieu Durand (Université du Maine/Laboratoire ESO). Esta reunión sirvió de preparación a la jornada de jóvenes americanistas que tendrá lugar en junio de 2015 sobre la misma temática.

Para incentivar «el compartir ideas», dos o tres estudiantes tienen que preparar una presentación sobre la temática. Cada estudiante escoge la forma que mejor le conviene: el compartir de experiencia de investigación, comentario de texto, síntesis de coloquio... Cada persona que interviene expone sus reflexiones en 10/15 minutas e introduce las preguntas que animan el debate que sigue.

Las propuestas deben hacerse un mes antes de la reunión, si hay varias propuestas, el tema es elegido en grupo.

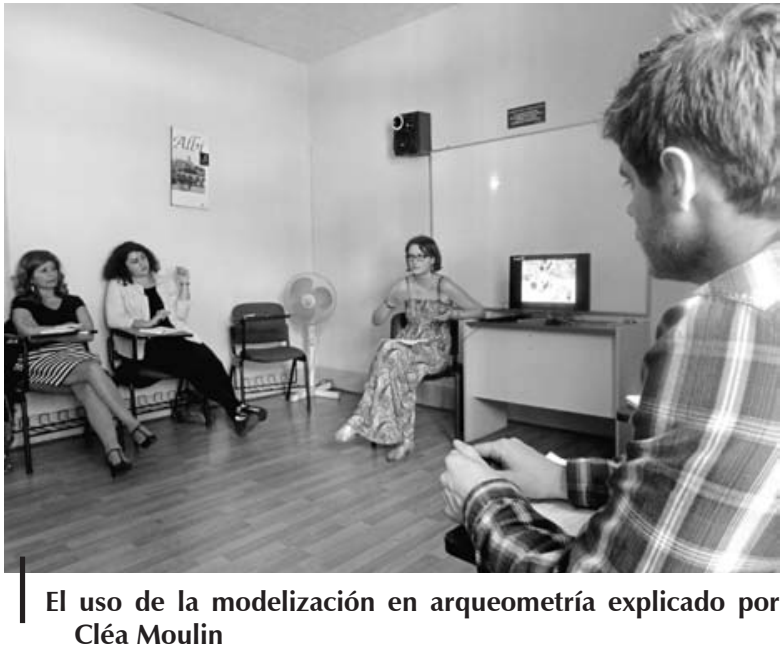

Por otra parte, el propósito es intercambiar metodologías y saberes específicos: realizar un power point, preparar un evento, seminario, preparar un trabajo de campo o entrevistas...

\section{DESPUÉS DE 10 REUNIONES UN BALANCE POSITIVO Y NECESIDAD DE CONSOLIDAR EL PROYECTO}

En 2014, la mayoría de las reuniones han tomado la forma de presentación de investigaciones (7 de las 10 reuniones: anexo 1). Varias disciplinas se cruzaron: Sociología, Historia, Antropología, Etnomusicología, Arqueología, y Geografía. Se han movilizado juntos varias competencias de organización y coordinación para que estas «tardes de jóvenes investigadores del IFEA» puedan perdurar en el tiempo. Este ejercicio necesita más rigor, especialmente para definir la agenda y animar las reuniones (moderador y secretaria). Se puede lamentar la ausencia de síntesis de las reuniones de este año. La organización debe consolidarse. 
Dos aportes deben ser subrayados. Por una parte, el grupo entendió muy rápidamente que estas reuniones tienen un carácter de formación. Cada encuentro multiplica las oportunidades de hablar en público en castellano, ejercicio necesario para la preparación de un oral. Por otra parte, el público no es pasivo, intercambia conocimientos con la persona que expone. Estas reuniones permiten descubrir el trabajo de cada uno y sus formas de trabajar en realidades sociales cada vez más complejas y diversas.

Gracias a la diversidad de las temáticas tratadas, se han cruzado varias teorías, metodologías y experiencias profesionales. Se intercambió acerca del papel del investigador en el Perú, su ética y el trabajo de reflexividad en cuanto al trabajo de campo: en los archivos (Alencar, R.; Rengifo, D.), en situación difícil por el recelo de los actores (Paux, C.), la conflictiva y violencia del tema de investigación (Constant, C; Durand, N.; Hattemer, C.) o a través de intercambios entre géneros (Buu-Sao, D.; Constant, C; Delevaux, M.; Hattemer, C.; Langlois, A.; Paux, C.).

El tema de los actores sociales fue muy debatido a través de la idea de organización en red (Alencar, R.; Leloup, E.; Peralta, P.) o del papel que juega un actor clave como los comerciantes (Alencar, R.; Codja, P.; Hattemer, C.; Peralta, P.). Finalmente se ha reflexionado acerca de conceptos contemporáneos desde el contexto peruano: identidad y cultura (Arce, M.; Delevaux, M.; Langlois, A.; Peralta, P.), o como el de territorio movilizado por historiadores, arqueólogos, sociólogos antropólogos y geógrafos (Housse; R.; Hattemer, C.; Langlois, A., Delevaux, M., Leloup, H.; Codja, P.) Estas reuniones no hubieran sido tan animadas sin la presencia de todos sus oyentes: desde jóvenes profesionales, estudiantes y practicantes. EL grupo ha podido contar con varias generaciones de investigadores: Gérard Borras (Director del IFEA), Mathieu Durand (Université du Maine/Laboratoire ESO), Pascale Metzger (IRD), Jérémy Robert (PUCP/IFEA), Carmen Salazar-Soler (CNRS/CERMA), Alexis Sierra (Univ. de Cergy-Pontoise/UMR Prodig), Alexandre Surrallés (CNRS/IFEA), Véronique Wright (IFEA). iAgradecemos a todas y todos por su participación!

\section{PERSPECTIVAS: CONSOLIDACIÓN DEL PROYECTO EN COLABORACIÓN CON EL IFEA E INTEGRACIÓN DE LOS OTROS PAÍSES}

La primera perspectiva es beneficiar del apoyo de la institución para consolidar el proyecto. Para lograr ese objetivo, los integrantes del taller tienen que contar con los investigadores presentes en el Perú, los becarios peruanos y franceses, y la red científica del IFEA, plataforma de investigación en América del Sur.

El IFEA acoge todo el año investigadores internacionales de distintas disciplinas, y sus estadías pueden beneficiar a los jóvenes investigadores. La intención es proponer una alternativa para el encuentro de varias redes. Estas reuniones permitirían reforzar los puentes entre diversas instancias universitarias. Finalmente, el IFEA podría también abrir sus puertas mensualmente a los estudiantes que vienen por su trabajo de campo en el Perú, Colombia, Ecuador, Bolivia y que necesitan una estructura de investigación y consejos. 
El grupo funciona en base a iniciativas y propuestas individuales (proposición de temas, invitados...) pero, sería preferible, por una cuestión de organización, proponer una agenda anual, definida con anticipación.

La consolidación del grupo necesita la creación de un «comité organizativo». Compartir las diversas actividades es esencial para el fortalecimiento del grupo. Se tienen que solucionar los problemas de cortas estadías de los jóvenes investigadores en Lima, y apoyarse eon el personal de la institución.

Finalmente, la perspectiva más ambiciosa, pero posible, es incluir la participación de nuestros colegas trabajando desde Bolivia, Ecuador, Colombia, Francia y el Cemca en México. Esa demanda fue formulada varias veces y subraya problemas vinculados con la logística. Todavía no se han resuelto los problemas para responder a esa demanda (discusión en vivo, sesiones conectadas a internet, espacio colaborativo para compartir bibliografías, y síntesis). Finalmente, se podría pensar en la apertura de nuevos espacios de intercambio en cada país donde cada miembro podría reunirse físicamente en un futuro cercano.

\section{Anexo 1: las tardes de jóvenes investigadores del IFEA en 2014}

Reunión temática «La ética en la investigación», viernes 4 de abril de 2014. «El software Sonal(C). Formación por Doris Buu-Sao (Sciences Po Paris/IFEA), viernes 9 de abril de 2014.

Reunión temática «Acceso a los datos de la investigación», viernes 30 de mayo de 2014.

«Circulación y mercantilización de bienes simbólicos: Implicancias económicas del culto al Señor de los Milagros en Madrid». Por Paola Peralta (Universidad de Nice Sophia Antipolis/Urmis), viernes 29 de agosto de 2014.

«Más allá del comercio directo: la presencia mercantil francesa en Lima (17101715)». Por Raúl Alencar (PUCP), comentario de Gérard Borras (Director del IFEA), viernes 26 de septiembre de 2014.

«De la valorización a la creación patrimonial; los mundos mineros en cuestión región Junín». Por Alice Langlois (EHESS/IFEA), viernes 31 de octubre de 2014.

Reunión temática «Ciudad y Conflicto», introducción al tema por Alexis Sierra (Université de Cergy Pontoise/UMR Prodig) y Mathieu Durand (Université du Maine/Laboratoire ESO), viernes 7 de noviembre de 2014.

Reunión antropología y etnomusicología. Con las intervenciones:

« Un trabajo con futuro? Las relaciones ambiguas de los wampis (jibaro) con el comercio y los comerciantes (Amazonas - Datem del Marañón)» por Paul Codjia (EHESS) y,

«Cantos rituales a la papa: las últimas wankas de Espinar (Cusco). Estudio y salvaguarda de una performance vocal andina antes de su extinción» por Manuel Arce Sotelo (Universidad Paris X Nanterre/IFEA), comentario de Alexandre Surrallés (CNRS/IFEA), viernes 28 de noviembre de 2014. 
Reunión arqueología. Con las intervenciones:

«De la experiencia del Master II a la construcción de una propuesta de investigación de doctorado» por Cléa Moulin (Universidad de Lund, Suecia) y,

«Territorialidad y conflictos entre la costa pacífica y el altiplano sur andino durante la época prehispánica tardía (1000-1450 d. C.). Avance del proyecto de tesis y primer resultado del trabajo de campo». Por Romuald Housse (Universidad Paris 1 Panthéon-Sorbonne/IFEA), comentario de Véronique Wright (IFEA), viernes 5 de diciembre de 2014.

Reunión geografía con un enfoque sobre Lima. Con las intervenciones:

«Agricultura y territorios periurbanos: el caso de las valles agrícolas de Lima» por Héloise Leloup (Universidad Paris 1 Panthéon-Sorbonne/UMR Prodig) y,

«iErradicar La Parada? Un análisis de las grandes tensiones que atraviesa la transformación de la ciudad de Lima». Por Cyriaque Hattemer (IFEA/Universidad Paris 1 Panthéon-Sorbonne/UMR Prodig), comentario de Pascale Metzger (IRD), viernes 12 de diciembre 2014.

\section{Cyriaque HATTEMER, Alice LANGLOIS}

Se agradece a Maud DELEVAUX por la traducción. 